\title{
Clinically Relevant Depressive Symptoms in Young Stroke Patients - Results of the sifap1 Study
}

\author{
Christian Tanislav $^{\mathrm{a}}$ Peter Kropp ${ }^{\mathrm{b}} \quad$ Ulrike Grittner $^{\mathrm{c}, \mathrm{d}}$ Martin Holzhausen ${ }^{c}$ \\ Franz Fazekas $^{\mathrm{e}}$ Gerhard Jan Jungehülsing ${ }^{d}$ Turgut Tatlisumak $^{f}$ \\ Bettina von Sarnowski ${ }^{g}$ Jukka Putaala ${ }^{f}$ Roman Huber ${ }^{\text {h }}$ Vincent Thijs ${ }^{i}$ \\ Reinhold Schmidt ${ }^{\mathrm{e}}$ Manfred Kaps ${ }^{\mathrm{a}}$ Christian Enzinger ${ }^{\mathrm{e}, j}$ Martin Dichgans ${ }^{\mathrm{k}}$ \\ Bo Norrving' Arndt Rolfs ${ }^{m}$
}

\begin{abstract}
${ }^{a}$ Neurology, Justus Liebig University, Giessen, ${ }^{b}$ Institute of Medical Psychology and Medical Sociology, University of Rostock, Rostock, 'Department for Biostatistics and Clinical Epidemiology, Charité-Universitätsmedizin Berlin, and ${ }^{\mathrm{d} C e n t e r}$ for Stroke Research, Charité-Universitätsmedizin Berlin, Berlin, Germany; ${ }^{\mathrm{D}}$ Department of Neurology, Medical University of Graz, Graz, Austria; ${ }^{f}$ Department of Neurology, Helsinki University Central Hospital, Helsinki, Finland; ${ }^{9}$ Department of Neurology, University of Greifswald, Greifswald, h Department of Neurology, Friedrichshafen, Germany; ${ }^{\mathrm{C} C l i n i c a l}$ and Experimental Neurology, Leuven, Belgium; 'Department of Radiology, Division of Neuroradiology, Medical University of Graz, Graz, Austria; ${ }^{\prime}$ Institute for Stroke and Dementia Research, Klinikum Grosshadern, Munich, Germany; 'Department of Clinical Neuroscience, Neurology, Lund University, Lund, Sweden; ${ }^{\mathrm{m}}$ Albrecht-Kossel-Institute for Neuroregeneration, University of Rostock, Rostock, Germany
\end{abstract}

\section{Key Words}

Young stroke · Depression · Acute cerebral ischemia . sifap1 1 Risk factors

\footnotetext{
Abstract

Background: Although post-stroke depression is widely recognized, less is known about depressive symptoms in the acute stage of stroke and especially in young stroke patients. We thus investigated depressive symptoms and their determinants in such a cohort. Methods: The Stroke in Young Fabry Patients study (sifap1) prospectively recruited a large multinational European cohort $(n=5,023)$ of patients with a cerebrovascular event aged $18-55$. For assessing clinically
}

relevant depressive symptoms (CRDS, defined by a BDIscore $\geq 18$ ) the self-reporting Beck Depression Inventory (BDI) was obtained on inclusion in the study. Associations with baseline parameters, stroke severity (National Institutes of Health Stroke Scale, NIHSS), and brain MRI findings were analyzed. Results: From the 2007 patients with BDI documentation, $202(10.1 \%)$ had CRDS. CRDS were observed more frequently in women (12.6 vs. $8.2 \%$ in men, $p<0.001)$. Patients with CRDS more often had arterial hypertension, diabetes mellitus, and hyperlipidemia than patients without CRDS (hypertension: 58.0 vs. $47.1 \%, p=0.017$; diabetes mel-

Christian Tanislav and Ulrike Grittner contributed equally to this work.

\section{KARGER 125}

(c) 2015 S. Karger AG, Base

0251-5350/15/0441-0030\$39.50/0

E-Mail karger@karger.com

www.karger.com/ned
Christian Tanislav, MD

Department of Neurology

Justus Liebig University

Klinikstrasse 33, DE-35392 Giessen (Germany)

E-Mail christian.tanislav@ neuro.med.uni-giessen.de 
litus: 17.9 vs. $8.9 \%, p<0.001$; hyperlipidemia: 40.5 vs. $32.3 \%$, $p=0.012)$. In the subgroup of patients with ischemic stroke or TIA $(n=1,832)$ no significant associations between CRDS and cerebral MRI findings such as the presence of acute infarcts ( 68.1 vs. $65.8 \%, p=0.666)$, old infarctions (63.4 vs. $62.1 \%, p=0.725$ ) or white matter hyper-intensities (51.6 vs. $53.7 \%, p=0.520$ ) were found. Conclusion: Depressive symptoms were present in $10.1 \%$ of young stroke patients in the acute phase, and were related to risk factors but not to imaging findings.

(c) 2015 S. Karger AG, Basel

\section{Introduction}

As a disabling disease, stroke has an enormous emotional impact $[1,2]$. In this context, depression is an important consequence, which influences stroke recovery $[1,3-5]$. Most of the studies on mood disorders were conducted in general stroke populations without focusing on young patients, although in those, depression is particularly relevant with impact on the social and occupational re-integration $[5,6]$. Recently, several studies on young stroke provided important information on age and gender distribution, risk factors, etiologic factors, and imaging findings $[7,8]$. However, data on mood disorders such as depression in this specific group are limited. Investigating the occurrence, distribution, clinical and imaging correlates of depressive symptoms in young stroke patients is important, as depression has severe consequences in terms of its impact on stroke recovery.

We therefore investigated depressive symptoms and potential determinants in acute young stroke patients included in the Stroke in Young Fabry Patients study (sifap1), a large multicentre European study on young stroke [8].

\section{Methods}

\section{Design of the Study}

The multinational sifap1 study (47 centers in 15 European countries) prospectively recruited (between April 2007 and January 2010) 5,023 patients aged 18-55 with a cerebrovascular event (CVE) to establish the prevalence of Fabry disease. Details of this study have been published previously [8]. The study was approved by the Ethics committees at the leading center and each study site. All patients or their legal representatives gave written informed consent. Inclusion criteria were CVE $<3$ months, age $18-55$ years, and cerebral MRI obtained within $\leq 1$ month of inclusion. Diagnostic procedures were in accordance with the European Stroke Organisation Guidelines [9].

Depressive Symptoms in Young Acute Strokes
A secondary aim of the sifap1 study was to better characterize the pattern of stroke in young patients collecting a broad range of clinical, laboratory, and radiological data using mandatory stringent standardized methods. The present secondary analysis aimed to investigate clinically relevant depressive symptoms (CRDS) and potential determinants such as demographics, risk factors, stroke severity, and imaging findings. CRDS were assessed on inclusion in the study with the Beck Depression Inventory (BDI).

\section{Baseline Characteristics}

A transient ischemic attack (TIA) was defined as a CVE with clinical symptoms lasting $<24 \mathrm{~h}$. Ischemic stroke subtypes were classified according to the published criteria in the Trial of Org 10172 in Acute Stroke Treatment (TOAST) [10]. Using information from medical history and concomitant medications we considered the following risk factors: diabetes, arterial hypertension, dyslipidemia, and cardiovascular disease (history of coronary artery, peripheral arterial or congestive heart disease, prior myocardial infarction, and/or valvular disease). Hypertension and dyslipidemia were defined according to national guidelines used at each study center. Anthropometric measurements (height, body weight in kilogram) obtained at study inclusion were used to calculate obesity according to body mass index (BMI $\geq 30)$. Details of further lifestyle risk factors were based on patients' self-report and standardized questionnaires. Tobacco use was considered in the case of those who were currently smoking or those who had quit smoking in the last 5 years. Regular drinking was defined as a consumption of at least one drink/week; higher consumption referred to more than five drinks a day at least once a month. Severity of stroke (NIHSS) was assessed within the first $48 \mathrm{~h}$ or at the time of maximal impairment. Short night sleep duration was defined as sleeping $\leq 6$ at night time per $24 \mathrm{~h}$. Physical inactivity was defined as walking less than 1 mile per day. Demographics (age, sex, and ethnicity) were included in the mandatory core data set collected by centers.

\section{Beck Depression Inventory}

The BDI is a 21-question multiple-choice self-reported questionnaire to measure the degree of depressive symptoms [11]. Each item has a set of four potential answer options, ranging in intensity. The score ranges from 0 to 63 ; scores of 18 or higher indicate CRDS $[2,11]$. The assessment was performed on inclusion in the study and was an optional procedure.

\section{Cerebral Magnetic Resonance Imaging (MRI)}

Cerebral MRI was mandatory for all study participants. Standardized MRI sequences were required by protocol (at least T2weighted and/or fluid-attenuated inversion recovery images and diffusion-weighted imaging sequences) [12]. All MR images were analyzed offline centrally by experienced readers blinded to clinical and demographic data (C.E., F.F., R.S.). For ischemic infarcts they noted infarct type and number, infarct location, size, and vascular territories involved by using the templates by Tatu et al. [12]. DWI sequences served to identify areas of acute ischemia $[12,13]$. Old infarcts were defined as areas of T2 hyperintensity with associated focal atrophy and/or containing fluid-filled spaces [12]. White matter hyperintensities (WMHs) were defined as lesions with high signal intensity on $\mathrm{T} 2$-weighted images in the absence of evidence for complete tissue destruction and were rat- 
ed according to the Fazekas scale [12]. Deep WMHs were classified as $0=$ absent, $1=$ punctuate, $2=$ early confluent, and $3=$ confluent; periventricular white matter hyperintensities $(\mathrm{PWMH})$ were stratified into: $0=$ absent; $1=$ pencil-thin lining; $2=$ halo of $\geq 5 \mathrm{~mm}$ thickness; 3 = irregular WMH extending into deep white matter [12]. The total number and location of microbleeds (defined on gradient-echo T2*-weighted images as areas of signal loss within the brain parenchyma not exceeding $5 \mathrm{~mm}$ in diameter) were recorded [12].

\section{Statistical Analyses}

First, descriptive analyses were conducted. Univariate analysis was established to test associations of several characteristics with CRDS. For the subgroup of patients with ischemic stroke and TIA, separate univariate analyses for men and women for the association between characteristics (including MRI findings) and CRDS were calculated.

A multiple logistics regression was conducted to test which characteristics were associated with CRDS in ischemic stroke and TIA patients after adjustment for other covariates. Only covariates with significant associations in univariate analyses were selected for the multiple regression models. All $p$ values were adjusted for center heterogeneity by using random effects models. A p value of $<0.05$ was considered statistically significant. No adjustment for multiple testing was applied. All statistical analyses were conducted using IBM $^{\mathbb{C}}$ SPSS $^{\mathbb{C}}$ Statistics $22\left(^{\circledR}\right.$ SPSS Inc., IBM Company, 2013, Chicago, Ill., USA) and SAS $9.3\left({ }^{(} 2010\right.$ SAS Institute Inc., Cary, N.C., USA).

\section{Results}

We obtained a BDI in 2007 from a total of 5,023 patients; 1,832 patients had an ischemic stroke or TIA and 100 patients had a primary hemorrhage; in 36 patients no stroke entity was documented, in further 39 other causes for stroke (e.g., cerebral vein thrombosis) were found. The comparison of patients with a BDI assessment versus those without a BDI assessment revealed no relevant differences in the proportions of diabetes and hypertension; patients with a BDI assessment were slightly younger (median 46 vs. 47 years, $\mathrm{p}=0.031$ ) and were less severely affected (NIHSS median 2 vs. 3, p = 0.001). Furthermore, a BDI assessment was obtained more often in patients with TIA, and less often in those with primary intracerebral hemorrhage and ischemic stroke (table 1).

The BDI score for the investigated population ranged from 0 to 47 (interquartile range: $1-11$ ) with a median of five. The median delay for the BDI assessment was five days after admission (interquartile range 1-11 days). Overall, CRDS were present in 202 patients $(10.1 \%)$; they occurred more often in female than in male patients (12.6 vs. $8.2 \%, \mathrm{p}<0.001)$. With increasing age, higher proportions of patients with CRDS were detected (fig. 1).

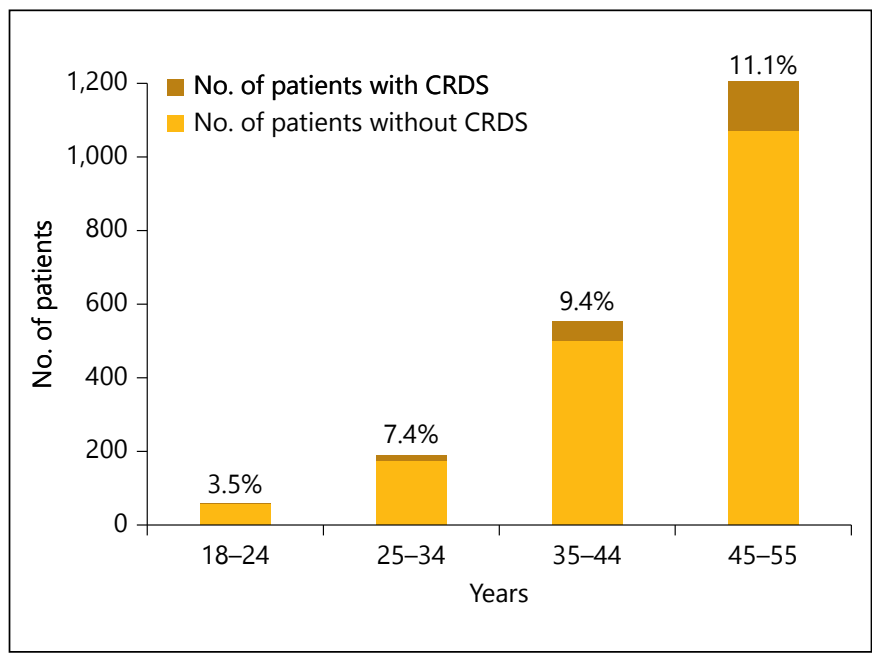

Fig. 1. Proportions of patients with clinically relevant depressive symptoms (CRDS) among different age classes. Percentages of patients with CRDS are indicated on each column.

Table 1. Comparison of young stroke patients with BDI-assessment versus those without

\begin{tabular}{lllll}
\hline & $\begin{array}{l}\text { Total } \\
\text { cohort } \\
(\mathrm{n}=5,023)\end{array}$ & $\begin{array}{l}\text { BDI } \\
\text { assessment } \\
(\mathrm{n}=2,007)\end{array}$ & $\begin{array}{l}\text { No BDI } \\
\text { assessment } \\
(\mathrm{n}=3,016)\end{array}$ & $\mathrm{p}$ \\
\hline $\begin{array}{l}\text { Sex, \% } \\
\text { Male }\end{array}$ & 59.0 & 57.3 & 60.0 & 0.391 \\
$\begin{array}{l}\text { Age median (IQR) } \\
\text { Stroke entity (n=4,806), \% }\end{array}$ & $46(40-51)$ & $46(41-51)$ & $47(40-51)$ & 0.031 \\
$\quad$ TIA & 22.3 & 26.2 & 19.6 & 0.004 \\
$\quad \begin{array}{l}\text { Ischemic stroke } \\
\text { Primary hemorrhage }\end{array}$ & 70.7 & 66.8 & 73.4 & \\
$\quad \begin{array}{l}\text { Other } \\
\text { Stroke severity (n=5,022) }\end{array}$ & 1.4 & 5.1 & 6.0 & \\
$\quad$ NIHSS median (IQR) & $3(1-6)$ & 2.0 & 1.0 & \\
$\begin{array}{c}\text { Risk factors, \% } \\
\text { Hypertension } \\
\quad(n=4,994)\end{array}$ & 47.0 & 48.2 & 46.2 & 0.054 \\
$\quad \begin{array}{llll}\text { Diabetes mellitus } \\
\quad(n=4,996)\end{array}$ & 10.0 & 9.8 & 10.2 & 0.224 \\
\hline
\end{tabular}

$\mathrm{BDI}=$ Beck depression inventory; $\mathrm{IQR}=$ interquartile range; $\mathrm{TIA}=$ transient ischemic attack; NIHSS = National institute of Health Stroke Scale.

While stroke severity was similar, patients with CRDS had more often arterial hypertension, diabetes mellitus, and dyslipidemia than patients without CRDS (hypertension: 58.0 vs. $47.1 \%, \mathrm{p}=0.017$; diabetes mellitus: 17.9 vs. $8.9 \%, \mathrm{p}<0.001$; dyslipidaemia: 40.5 vs. $32.3 \%, \mathrm{p}=0.012$ ) (table 2). 
Table 2. Baseline characteristics in young stroke patients with depressive symptoms

\begin{tabular}{|c|c|c|c|c|}
\hline & $\begin{array}{l}\text { Total cohort } \\
(\mathrm{n}=2,007)\end{array}$ & $\begin{array}{l}\text { No or mild depressive } \\
\text { symptoms } \\
\text { BDI }<18(\mathrm{n}=1,805)\end{array}$ & $\begin{array}{l}\text { Clinically relevant } \\
\text { depressive symptoms } \\
\text { BDI } \geq 18(n=202)\end{array}$ & $\mathrm{p}$ \\
\hline \multicolumn{5}{|l|}{ Sex, n (\%) } \\
\hline Male & $1,151(57.3)$ & $1,057(58.6)$ & $94(46.5)$ & $<0.001$ \\
\hline \multicolumn{5}{|l|}{ Age, n (\%) } \\
\hline $18-24$ years & $59(2.9)$ & $57(3.2)$ & $2(1.0)$ & 0.024 \\
\hline $35-44$ years & $552(27.5)$ & $500(27.7)$ & $52(25.7)$ & \\
\hline $45-55$ years & $1,206(60.1)$ & $1,072(59.4)$ & $134(66.3)$ & \\
\hline Time delay admission to BDI, n (\%) & $(\mathrm{n}=1,727)$ & $(\mathrm{n}=1,545)$ & $(\mathrm{n}=182)$ & \\
\hline$\leq 7$ days & $1,160(67.2)$ & $1,048(67.8)$ & $112(61.5)$ & 0.558 \\
\hline 8-14 days & $312(18.1)$ & $273(17.7)$ & $39(21.4)$ & \\
\hline 15-28 days & $129(7.5)$ & $114(7.4)$ & $15(8.2)$ & \\
\hline $15-28$ days & $118(7.4)$ & $104(7.2)$ & $14(8.5)$ & \\
\hline$>28$ days & $114(7.1)$ & $102(7.1)$ & $12(7.3)$ & \\
\hline Stroke entity, n (\%) & $(\mathrm{n}=1,971)$ & $(\mathrm{n}=1,771)$ & $(\mathrm{n}=200)$ & \\
\hline TIA & $516(26.2)$ & $461(26.0)$ & $55(27.5)$ & 0.568 \\
\hline Ischemic stroke & $1,316(66.8)$ & $1,192(67.3)$ & $124(62.0)$ & \\
\hline Primary hemorrhage & $100(5.1)$ & $84(4.7)$ & $16(8.0)$ & \\
\hline Other & $39(2.0)$ & $34(1.9)$ & $5(2.5)$ & \\
\hline \multicolumn{5}{|l|}{ Stroke severity $(\mathrm{n}=2,007)$} \\
\hline NIHSS median (IQR) & $2(1-5)$ & $2(1-5)$ & $3(1-6)$ & 0.130 \\
\hline In males $(\mathrm{n}=1,151)$ & $3(1-5)$ & $3(1-5)$ & $3(1-7)$ & 0.106 \\
\hline In females $(\mathrm{n}=856)$ & $2(1-5)$ & $2(1-4)$ & $3(1-6)$ & 0.390 \\
\hline \multicolumn{5}{|l|}{ Risk factors, $\mathrm{n}(\%)$} \\
\hline Obstructive sleep apnea $(\mathrm{n}=1,970)$ & $72(3.7)$ & $63(3.6)$ & $9(4.5)$ & 0.395 \\
\hline Sleep $\leq 6 \mathrm{~h}$ at night time $(\mathrm{n}=2,006)$ & $367(18.3)$ & $339(18.8)$ & $28(13.9)$ & 0.052 \\
\hline Regular alcohol consumption $^{\dagger}(\mathrm{n}=1,997)$ & $1,017(50.9)$ & $924(51.4)$ & $93(46.5)$ & 0.434 \\
\hline Higher alcohol consumption ${ }^{\ddagger}(\mathrm{n}=1,949)$ & $650(33.4)$ & $589(33.6)$ & $61(31.3)$ & 0.375 \\
\hline
\end{tabular}

* Current smoking or quit within last 5 years. ${ }^{* *}$ Cardiovascular disease considers one of the following conditions: ischemic coronary artery disease, myocardial infarctions, peripheral artery occlusive disease, congestive heart failure and valvular disease. ${ }^{* * *}<1$ mile per day walking. ${ }^{\dagger}$ Consumption of at least one drink/week. ${ }^{\ddagger} 5$ drinks a day at least once a month. BDI= Beck depression inventory; IQR= interquartile range; TIA = transient ischemic attack; NIHSS = National Institute of Health Stroke Scale.

In the subgroup of patients with ischemic stroke or TIA ( $\mathrm{n}=1,832)$, CRDS also occurred more frequently in females ( 11.8 vs. $8.3 \%, p=0.014)$. The results of the analysis conducted within this group of patients (with stroke or TIA) is presented in tables 3 and 4 . In both sexes, those with CRDS had more often a CVE caused by large artery atherosclerosis (male: 29.4 vs. $19.3 \%$; female: 17.6 vs. $11.8 \%$ ) but less often caused by cardioembolic strokes (male: 7.1 vs. $15.2 \%$; female: 13.2 vs. $16.1 \%$ ), (table 3 ). The presence of vascular risk factors including hypertension, diabetes mellitus and hyperlipidemia was associated with the occurrence of CRDS in both sexes (table 3). 
Table 3. Differences in baseline characteristics between patients with no or mild depressive symptoms versus with clinically relevant depressive symptoms in the subgroup of patients with ischemic stroke or TIA by sex

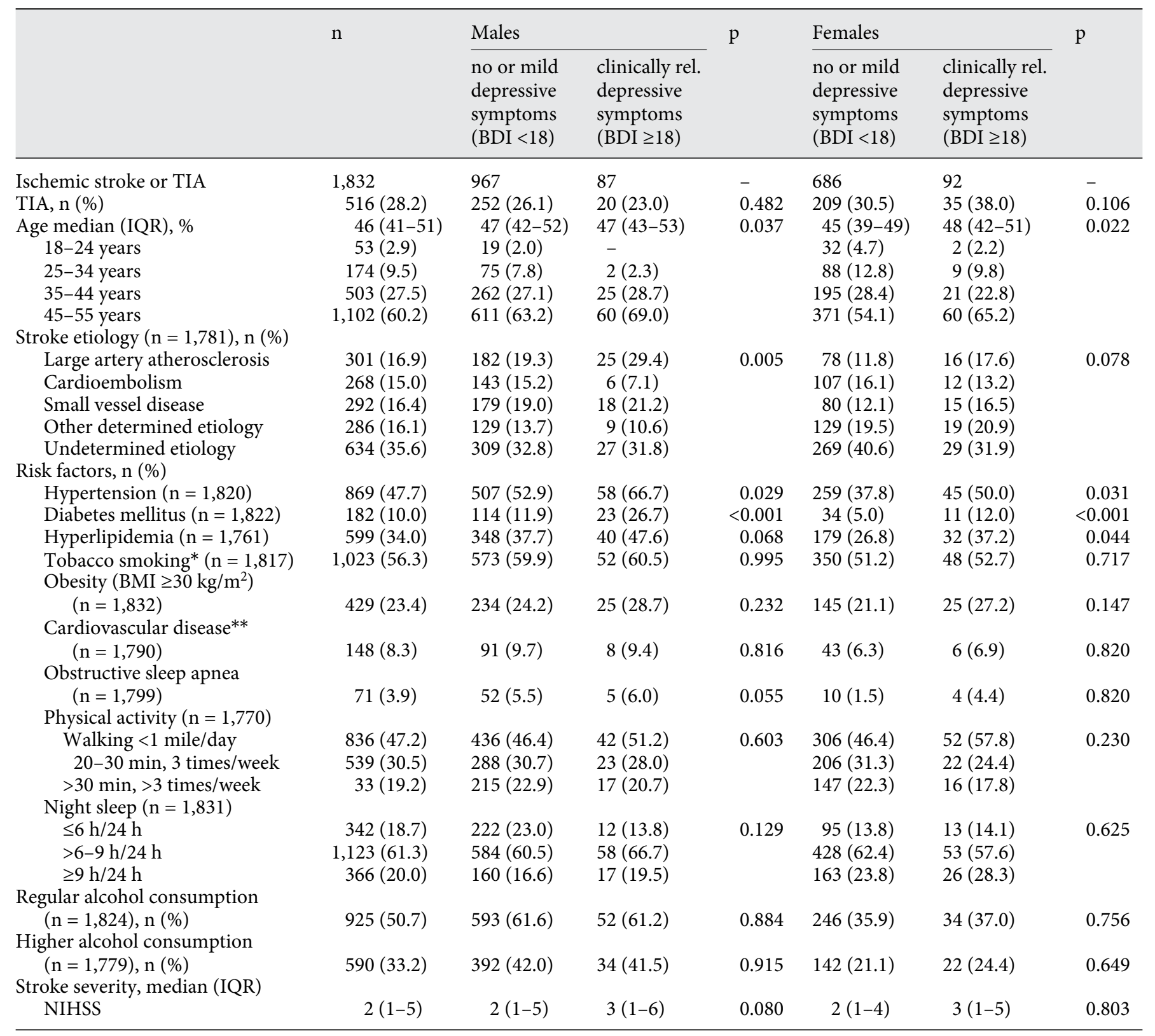

* Current smoking or quit within last 5 years. ${ }^{* *}$ Cardiovascular disease considers one of the following conditions: ischemic coronary artery disease, myocardial infarctions, peripheral artery occlusive disease, congestive heart failure and valvular disease. ${ }^{\dagger}$ Consumption of at least one drink/week. ${ }^{\ddagger} 5$ drinks a day at least once a month. BDI = Beck depression inventory; IQR = interquartile range; TIA = transient ischaemic attack; NIHSS = National Institute of Health Stroke Scale.

Out of 1,832 patients with ischemic stroke or TIA, 1,730 patients had a cerebral MRI. No specific brain imaging findings were associated with the occurrence of CRDS (table 4). In CRDS patients, white matter hyperintensities (WMH) were not more frequent in patients with CRDS versus those without (deep WMH as well as periventricular WMH) (male: 47.4 vs. $47.3 \%, \mathrm{p}=0.734$; female: 49.4 vs. $44.9 \%, \mathrm{p}=0.575$ ) (table 4); even after stratifying WMH according to their severity no relevant differences between patients with versus without CRDS were noted (table 4). 
Table 4. Brain imaging findings between patients with no or mild depressive symptoms versus with clinically relevant depressive symptoms in the subgroup of patients with ischemic stroke or TIA by sex

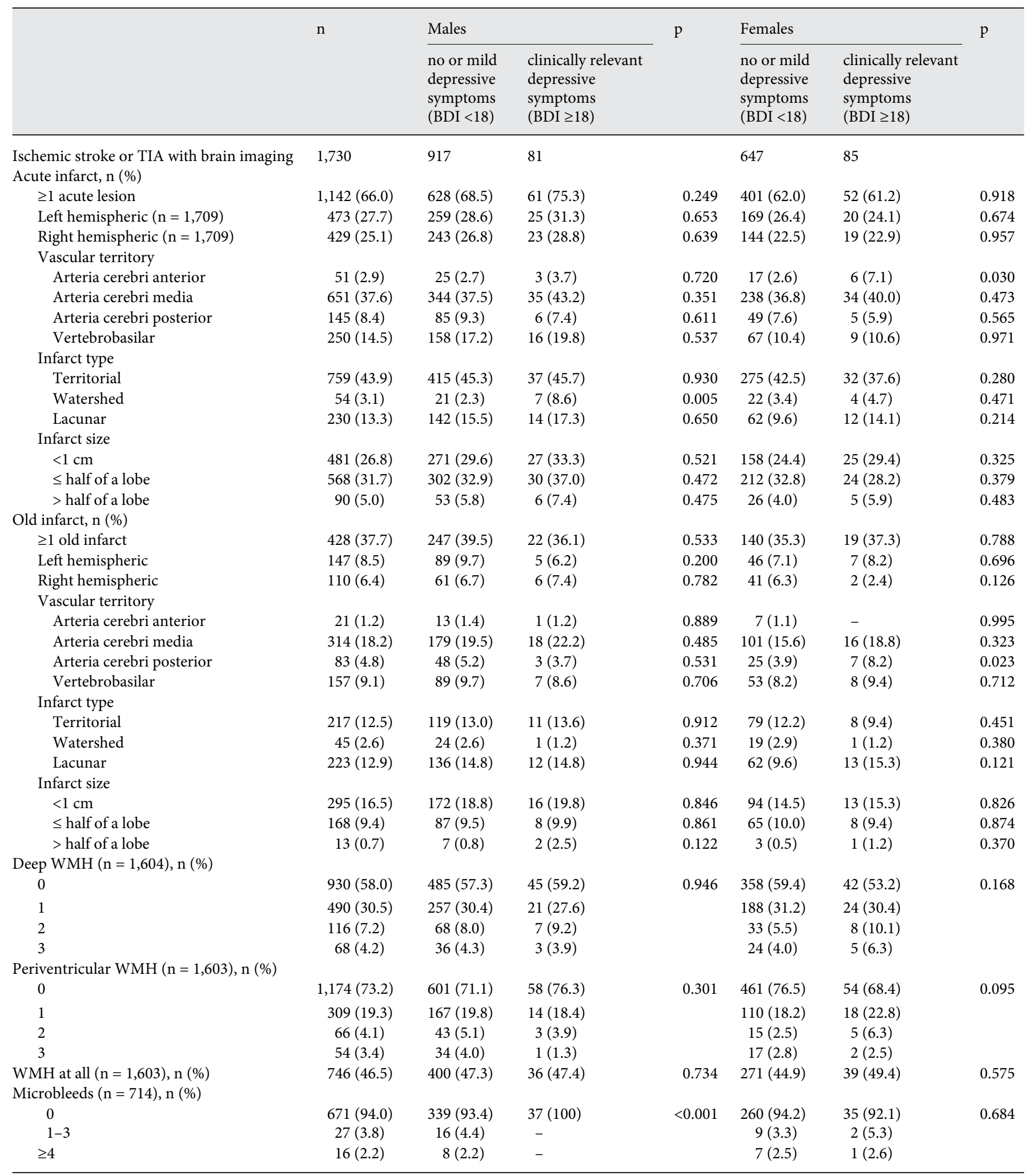

$\mathrm{BDI}=$ Beck depression inventory; TIA = transient ischaemic attack; $\mathrm{WMH}=$ white matter hyperintensities. 
Table 5. Multiple logistic regression for clinically relevant depressive symptoms $(\mathrm{BDI} \geq 18)$ in those patients with ischemic stroke or TIA ( $\mathrm{n}=1,701,41$ centers) (mixed model with random intercept)

\begin{tabular}{lcr}
\hline & OR $(95 \% \mathrm{CI})$ & $\mathrm{p}$ \\
\hline Fixed effects & & \\
Sex & $1.81(1.32-2.49)$ & 0.001 \\
Age (in decades) & $1.28(0.98-1.67)$ & 0.072 \\
Diabetes & $2.04(1.46-2.86)$ & $<0.001$ \\
Hypertension & $1.27(0.83-1.93)$ & 0.271 \\
Hyperlipidemia & $1.12(0.80-1.55)$ & 0.521 \\
Stroke etiology (reference: undetermined etiology) & \\
$\quad$ Arteriosclerotic & $1.53(1.00-2.32)$ & 0.066 \\
$\quad$ Cardioembolism & $0.78(0.51-1.18)$ & \\
$\quad$ Small vessel & $1.13(0.79-1.61)$ & \\
$\quad$ Other determined & $1.21(0.75-1.94)$ & \\
\hline Random effects & & $<0.001$ \\
Between centre variance & $0.29(0.11)$ & \\
\hline
\end{tabular}

In the logistic regression analysis after adjusting for other relevant covariates female sex (OR 1.81, 95\% CI 1.32-2.49) and diabetes mellitus (OR 2.04, 95\% CI 1.462.86) were associated with CRDS (table 5).

\section{Discussion}

In this specific group of acute young strokes (18-55 years), we found $10.1 \%$ harboring CRDS in the early stage of their disease. The occurrence of CRDS was associated with the female sex and the presence of diabetes mellitus. Stroke severity and brain MRI lesion characteristics did not affect the occurrence of CRDS.

To view our results in an appropriate context and compare them with other investigations on depression in the acute phase of stroke, different aspects need to be considered: studies investigating mood disorders included patients mainly without age restriction and the definitions of disorders, instruments and the time intervals for the assessment differed widely [14]. In the sifap1 study depressiveness was assessed in the early stage of stroke (median 5 days after admission). For comparison few investigations in acute hospitalized strokes are available. In such studies relevant depressive symptoms were reported in $12-14 \%$ of the patients [15-17]. Hence, the rate of CRDS depicted in sifap1 (10.1\%) is comparable to these results especially when considering that we examined a cohort of young strokes.

It needs to be considered, however, that a substantial proportion of patients seem to develop CRDS beyond the acute phase. In the FINNSTROKE study, BDI-values $>18$ were found in $24 \%$ of the patients at three months after the CVE; one year later the proportion rose to $30 \%$. The obviously small proportion of depressed stroke patients in the acute stage and the high depression incidence within the first year render specific therapeutic measurements necessary, with potential benefit in avoiding this complication. Especially in young stroke, this approach deserves more attention in the rehabilitation process. Positive effects in recovery could be expected, allowing potentially quicker social and occupational reintegration and in particular the restart of professional activities.

In our study, females with acute stroke suffered more often from CRDS than males. This finding was also depicted in previous studies conducted in general stroke populations $[2,18-20]$. As an explanation, the authors speculated that many stroke patients are older women living alone $[2,19,20]$. In sifap1 young stroke patients were recruited; thus, our results cannot be explained by loneliness of older women. Other mechanisms such as genetic predisposition, fluctuating hormone levels in women or direct psychological issues such as coping with traumatic events appear to be more relevant [21-23]. Facing the high psychological impact related to a CVE, sexspecific coping strategies could be relevant for explaining sex differences regarding CRDS in our patients. The tendency for developing depressive symptoms after stroke more often in older ages could also be observed in our study [18]. In both sexes, the oldest age group of 45-55 years exhibited the largest proportion of patients with CRDS.

The relationship between WMH and mood disorders is contradictory. While some authors suggest WMH may play a role in the development of mood disorders, others report no association between WMH and depressive symptoms [24-29]. When dealing with stroke patients, no relation between post-stroke depressive symptoms and pre-existing $\mathrm{WMH}$ in the brain could be ascertained $[26,29,30]$. An association of WMH and delayed mood disorders after stroke has been described, but no relevance for the development of depressive symptoms in the acute stage $[16,30]$ has been found. Accordingly, our findings are in line with these findings; in our study, $\mathrm{WMH}$ (at all or stratified by severity) were not associated with the occurrence of CRDS. Acute ischemic lesions were also not associated with CRDS, in contrast to investigations claiming a relevance of lesion's location such as the affected region $[26,30]$. Overall, our findings suggest that in young stroke patients, depressive symptoms in the
36

Neuroepidemiology 2015;44:30-38 DOI: $10.1159 / 000371389$
Tanislav et al. 
acute stage are rather related to a psychological reactive phenomenon to the event itself than to pre-existing or acute lesions of the brain.

Scarce evidence exists indicating the association of vascular risk factors with the occurrence of depression after stroke $[25,31]$. The multiple logistic regression analysis in the subgroup of patients with ischemic stroke or TIA showed that apart from sex diabetes mellitus there remained an independent parameter associated with CRDS after controlling for other relevant characteristics. In this context, stroke subtypes favored by vascular risk factors did not emerge as independent factors. The reasons for the association of diabetes mellitus and depression after stroke remain unclear, albeit differences in cognitive performance could play a role. This hypothesis arises from recent studies showing that diabetes might independently determine cognitive decline in vascular patients [32].

In our study, depressive symptoms were investigated with a validated standard tool for assessing CRDS, but no cognition assessments were provided. This is one of the main limitations of the present investigation; in several investigations, the cognitive status featured as a main determinant for depressive symptoms irrespective of current circumstances. A further limitation represents the lack of a direct control group for comparison. Sifap1 was designed for establishing the prevalence of Fabry disease in an unselected population of young stroke patients; thus a cross-sectional investigation was the appropriate choice. However, data derived from case control studies suggest that CRDS in young healthy individuals are less frequent than in sifap1 [33-36]. As the BDI-assessment was an optional item within the study, it was not done in all study participants. In this context, the selection bias of exclusion of patients more severely affected by stroke form $\mathrm{BDI}$ assessment needs to be considered when interpreting our results, whereas there was no such bias with regard to sex. The BDI is a self-reporting assessment for investigat- ing depressive symptoms. Even validated for the utilization in this manner, a verification of the diagnosis in a direct consultation or examination by specialists was not allocated. This might represent another limitation especially among patients with low scores in the BDI assessment.

\section{Conclusion}

In summary, we detected CRDS in $10.1 \%$ of young acute stroke patients early after the event. Parameters such as characteristics of acute lesions or the presence of $\mathrm{WMH}$ were not associated with the presence of CRDS. Diabetes mellitus was the most important parameter associated with CRDS. In female patients, CRDS occurred more often as compared to male individuals, probably due to different strategies in coping with traumatic events. Further investigations in young strokes are required to prove the long-term follow up of CRDS. This is especially of interest for the development of tailored treatment strategies for the rehabilitation, potentially beneficial for the recovery process.

\section{Disclosure Statement}

All authors report no conflicts of interest or competing interests related to the presented manuscript.

\section{Study Funding}

The sifapl study (Stroke in Young Fabry Patients, www.sifap. eu, www.clinicaltrials.gov: No. NCT00414583) has been supported partially by an unrestricted scientific grant from Shire Human Genetic Therapies. The sponsors of the study had no role in the study design, data collection, data analysis, interpretation, writing of the manuscript, or the decision to submit the manuscript for publication.

\section{References}

1 Andersen G, Vestergaard K, Riis J, Lauritzen L: Incidence of post-stroke depression during the first year in a large unselected stroke population determined using a valid standardized rating scale. Acta Psychiatr Scand 1994;90:190-195.

2 Kotila M, Numminen H, Waltimo O, Kaste M: Depression after stroke: results of the FINNSTROKE Study. Stroke 1998;29:368-372.

3 Astrom M, Adolfsson R, Asplund K: Major depression in stroke patients. A 3-year longitudinal study. Stroke 1993;24:976-982.
4 Hackett ML, Anderson CS, House AO: Management of depression after stroke: a systematic review of pharmacological therapies. Stroke 2005;36:1098-1103.

5 Sienkiewicz-Jarosz H, Milewska D, Bochynska A, Chelmniak A, Dworek N, Kasprzyk K, Galecka K, Szczepanska-Szarej A, Chwojnicki K, Zyluk B, Slowik A, Ryglewicz D: Predictors of depressive symptoms in patients with stroke - a three-month follow-up. Neurol Neurochir Pol 2010;44:13-20.
6 Hackett ML, Hill KM, Hewison J, Anderson CS, House AO: Stroke survivors who score below threshold on standard depression measures may still have negative cognitions of concern. Stroke 2010;41:478-481.

7 Putaala J, Metso AJ, Metso TM, Konkola N, Kraemer Y, Haapaniemi E, Kaste M, Tatlisumak T: Analysis of 1008 consecutive patients aged 15 to 49 with first-ever ischemic stroke: the Helsinki young stroke registry. Stroke 2009;40:1195-1203. 
8 Rolfs A, Fazekas F, Grittner U, Dichgans M, Martus P, Holzhausen M, Bottcher T, Heuschmann PU, Tatlisumak T, Tanislav C, Jungehulsing GJ, Giese AK, Putaala J, Huber R, Bodechtel U, Lichy C, Enzinger C, Schmidt R, Hennerici MG, Kaps M, Kessler C, Lackner K, Paschke E, Meyer W, Mascher H, Riess O, Kolodny E, Norrving B: Acute cerebrovascular disease in the young: the Stroke in Young Fabry Patients study. Stroke 2013;44:340349.

-9 European Stroke Organisation (ESO) Executive Committee; ESO Writing Committee: Guidelines for management of ischaemic stroke and transient ischaemic attack 2008. Cerebrovasc Dis 2008;25:457-507.

10 Adams HP Jr, Bendixen BH, Kappelle LJ, Biller J, Love BB, Gordon DL, Marsh EE 3rd: Classification of subtype of acute ischemic stroke. Definitions for use in a multicenter clinical trial. TOAST. Trial of Org 10172 in Acute Stroke Treatment. Stroke 1993;24:3541.

-11 Beck AT, Ward CH, Mendelson M, Mock J, Erbaugh J: An inventory for measuring depression. Arch Gen Psychiatry 1961;4:561571.

12 Fazekas F, Enzinger C, Schmidt R, Dichgans M, Gaertner B, Jungehulsing GJ, Hennerici MG, Heuschmann P, Holzhausen M, Kaps M, Kessler C, Martus P, Putaala J, Ropele S, Tanislav C, Tatlisumak T, Norrving B, Rolfs A: MRI in acute cerebral ischemia of the young: the Stroke in Young Fabry Patients (sifap1) Study. Neurology 2013;81:1914-1921.

-13 Tatu L, Moulin T, Bogousslavsky J, Duvernoy $\mathrm{H}$ : Arterial territories of the human brain: cerebral hemispheres. Neurology 1998;50: 1699-1708.

-14 Hackett ML, Yapa C, Parag V, Anderson CS: Frequency of depression after stroke: a systematic review of observational studies. Stroke 2005;36:1330-1340.

15 Morris PL, Robinson RG, Raphael B: Prevalence and course of depressive disorders in hospitalized stroke patients. Int J Psychiatry Med 1990;20:349-364.

16 Nys GM, van Zandvoort MJ, van der Worp HB, de Haan EH, de Kort PL, Kappelle LJ: Early depressive symptoms after stroke: neuropsychological correlates and lesion characteristics. J Neurol Sci 2005;228:27-33.

-17 Snaphaan L, van der Werf S, Kanselaar K, de Leeuw FE: Post-stroke depressive symptoms are associated with post-stroke characteristics. Cerebrovasc Dis 2009;28:551-557.

18 Hackett ML, Anderson CS: Predictors of depression after stroke: a systematic review of observational studies. Stroke 2005;36:22962301.
19 Sharpe M, Hawton K, Seagroatt V, Bamford J, House A, Molyneux A, Sandercock P, Warlow C: Depressive disorders in long-term survivors of stroke. Associations with demographic and social factors, functional status, and brain lesion volume. Br J Psychiatry 1994; 164:380-386.

20 Wade DT, Legh-Smith J, Hewer RA: Depressed mood after stroke. A community study of its frequency. Br J Psychiatry 1987; 151:200-205.

21 Jafari F, Hadizadeh MH, Zabihi R, Ganji K: Comparison of depression, anxiety, quality of life, vitality and mental health between premenopausal and postmenopausal women. Climacteric 2014;17:660-665.

22 Schiltz L, Ciccarello A, Ricci-Boyer L, Schiltz J: Defence mechanisms and coping strategies in men and women: a comparative and structural study based on the artistic production of people suffering from a break-up of their life project. Bull Soc Sci Med Grand Duche Luxemb 2013;2:7-24.

23 Strohmaier J, Amelang M, Hothorn LA, Witt SH, Nieratschker V, Gerhard D, Meier S, Wust S, Frank J, Loerbroks A, Rietschel M, Sturmer T, Schulze TG: The psychiatric vulnerability gene CACNA1C and its sex-specific relationship with personality traits, resilience factors and depressive symptoms in the general population. Mol Psychiatry 2013;18: 607-613.

24 Firbank MJ, O’Brien JT, Pakrasi S, Pantoni L, Simoni M, Erkinjuntti T, Wallin A, Wahlund LO, van Straaten I, Inzitari D: White matter hyperintensities and depression - preliminary results from the LADIS study. Int J Geriatr Psychiatry 2005;20:674-679.

25 Hajjar I, Quach L, Yang F, Chaves PH, Newman $\mathrm{AB}$, Mukamal K, Longstreth W Jr, Inzitari M, Lipsitz LA: Hypertension, white matter hyperintensities, and concurrent impairments in mobility, cognition, and mood: the Cardiovascular Health Study. Circulation 2011;123:858-865.

26 Iosifescu DV, Renshaw PF, Dougherty DD, Lyoo IK, Lee HK, Fraguas R, Cassano P, Nierenberg AA, Fava M: Major depressive disorder with anger attacks and subcortical MRI white matter hyperintensities. J Nerv Ment Dis 2007;195:175-178.
27 Jorm AF, Anstey KJ, Christensen H, de Plater G, Kumar R, Wen W, Sachdev P: MRI hyperintensities and depressive symptoms in a community sample of individuals 60-64 years old. Am J Psychiatry 2005; 162:699705 .

28 Serafini G, Pompili M, Innamorati M, Negro A, Fiorillo M, Lamis DA, Erbuto D, Marsibilio F, Romano A, Amore M, D'Alonzo L, Bozzao A, Girardi P, Martelletti P: White matter hyperintensities and self-reported depression in a sample of patients with chronic headache. J Headache Pain 2012;13:661-667.

29 Versluis CE, van der Mast RC, van Buchem MA, Bollen EL, Blauw GJ, Eekhof JA, van der Wee NJ, de Craen AJ: Progression of cerebral white matter lesions is not associated with development of depressive symptoms in elderly subjects at risk of cardiovascular disease: The PROSPER Study. Int J Geriatr Psychiatry 2006;21:375-381.

30 Kim JT, Park MS, Yoon GJ, Jung HJ, Choi KH, Nam TS, Lee SH, Choi SM, Kim BC, Kim MK, Cho KH: White matter hyperintensity as a factor associated with delayed mood disorders in patients with acute ischemic stroke. Eur Neurol 2011;66:343-349.

31 Spalletta G, Guida G, De Angelis D, Caltagirone C: Predictors of cognitive level and depression severity are different in patients with left and right hemispheric stroke within the first year of illness. J Neurol 2002;249:15411551.

32 Dhamoon MS, Moon YP, Paik MC, Sacco RL, Elkind MS: Diabetes predicts long-term disability in an elderly urban cohort: the Northern Manhattan Study. Ann Epidemiol 2014; 24:362-368.

-33 Benito-Leon J, Labiano-Fontcuberta A, Mitchell AJ, Moreno-Garcia S, MartinezMartin P: Multiple sclerosis is associated with high trait anger: A case-control study. J Neurol Sci 2014;340:69-74.

34 Grases G, Colom MA, Fernandez RA, CostaBauza A, Grases F: Evidence of higher oxidative status in depression and anxiety. Oxid Med Cell Longev 2014;2014:430216.

-35 Ramiro Fde S, Lombardi Junior I, da Silva RC, Montesano FT, de Oliveira NR, Diniz RE, Alambert PA, Padovani Rda C: Investigation of stress, anxiety and depression in women with fibromyalgia: a comparative study. Rev Bras Reumatol 2014;54:27-32.

36 Uglesic B, Lasic D, Zuljan-Cvitanovic M, Bukovic D, Karelovic D, Delic-Brkljacic D, Bukovic N, Radan M: Prevalence of depressive symptoms among college students and the influence of sport activity. Coll Antropol 2014; $38: 235-239$. 